\title{
Strategic Challenges of Mergers and Acquisitions in the Higher Education Sector
}

\author{
Łukasz Sułkowski, Robert Seliga, Andrzej Woźniak
}

\begin{abstract}
A B S T R A C T
Objective: The aim of the article is to present the issue of mergers and acquisitions of universities with reference to academic entrepreneurship.

Research Design \& Methods: The research methodology in the article was based on comparative analysis of case studies of universities mergers. The article is of an illustrative nature and constitutes a starting point for further in-depth research in the field of university mergers and academic entrepreneurship.
\end{abstract}

Findings: One of the consolidation motivations in France was to build strong links between universities and enterprises, which is supposed to fuel economic, scientific and technological development. Key mechanisms to drive a wave of strategic mergers in the public university sector that is sweeping through the world are global rankings.

Implications \& Recommendations: Consolidations of HEls should also based on effective human capital management and entrepreneurial organisational culture. Nowadays, in the process of university merger research, we are at the induction stage, where hundreds of case studies and few comparative studies have been gathered that draw a complex picture of mergers and can serve as a source of practical guidance.

Contribution \& Value Added: International comparison of mergers of Polish and French public universities that lead to recommendations on macro level of public policy and on mezzo and micro level of university management.

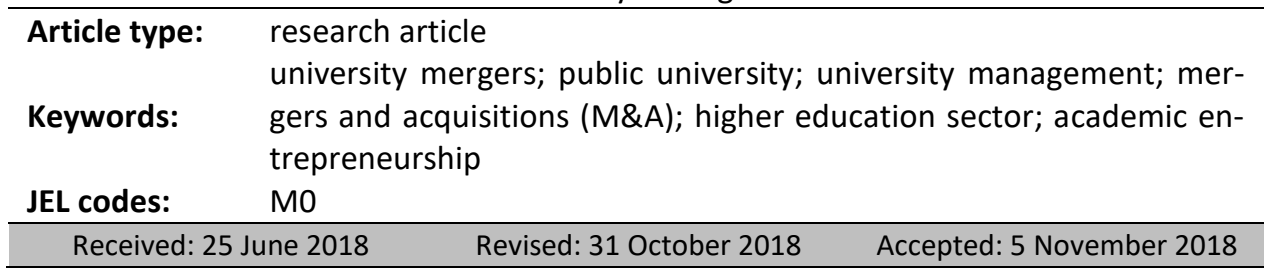

\section{Suggested citation:}

Sułkowski, Ł., Seliga, R., \& Woźniak, A. (2019). Strategic Challenges of Mergers and Acquisitions in Higher Education Sector. Entrepreneurial Business and Economics Review, 7(2), 199-215. https://doi.org/10.15678/EBER.2019.070211 


\section{INTRODUCTION}

A characteristic feature of modern economy is the existence of many different economic entities that can be grouped according to the type of their business activity. Business entities, most often enterprises, operate within the framework of meso-structures taking a competitive (competitive sector) and sometimes a synergistic form (cluster). The higher education sector is atypical because it is dominated by non-enterprise economic entities, and competitiveness is regulated and limited by state intervention. The rapid development of the higher education sectors all over the world is, moreover, associated with the growing importance of intellectual capital and the transfer of knowledge that distinguishes modern economies from industrial economies (Mačerinskiene \& Aleknavičiūtè, 2017). In this sense, the higher education sector is the backbone and the source of most modern production and service sectors. The issue of competitiveness is a strategic problem both from the point of view of the development of the entire sector and the market players operating in it. M.E. Porter analyses the relation between the competitiveness and profitability of an economic entity and the attractiveness of the sector in which this entity operates.

The merger process that is currently taking place in the higher education sector can be called 'merger-mania'. In an attempt to analyse literature and research results in the field of university mergers, it can be noted that in some educational systems it is already an advanced process of a hundred years or more. Extensive merger programmes are or have been implemented in China, South Africa, the USA, France and Norway, among others. In many countries strategic mergers of large public universities are being implemented. It happened in Finland, Sweden, France and even Vietnam (Pinheiro, Geschwind, \& Aarrevaara, 2016). In most countries the consolidation of universities is a bottom up process, but the tendencies to connect at the central level are reflected in public policies. In some countries, for example in South Africa, Russia, China and Norway, top-down consolidations, which are more controversial, are also conducted (Karodia, Shaikh, \& Soni, 2015). The objectives of mergers are therefore diverse and may include: entry into the 'world league of universities', rationalisation of education and research networks, as well as restructuring aimed at increasing the efficiency of the education process (Cai, 2016). A specific objective pursued through mergers may be to increase the access and quality of higher education addressed to disadvantaged groups. This was the idea of consolidation and transformation of higher education in South Africa.

The aim of the article is to present the issue of mergers and acquisitions of universities with reference to academic entrepreneurship. The research methodology in the article was based on a case study of the university. The article is of an illustrative nature and constitutes a starting point for further in-depth research in the field of university mergers and academic entrepreneurship.

The structure of the article is organised in the following way. In first part literature review about mergers and acquisitions in higher education sector was conducted. Secondly, the methodology was described. Thirdly, results and discussion were presented. The article ends with the conclusion. 


\section{LITERATURE REVIEW}

When attempting to analyse management processes at universities, it can be noticed that many classical management concepts have been implemented into these processes. This implementation has the characteristics of adaptation, which takes into account the broad specifics of educational services at the higher level. Universities provide educational services and operate in an environment that has a major impact on their activities (Soni \& Govender, 2018). Therefore, the choice of strategy depends to a large extent on such factors as the legal form of the university or its specialisation (Mihi-Ramirez, 2016).

Looking forward, it can be stated that the university of the future will largely rely on strategies that will be integrated with the university's organisation, will be supported by analytical and IT tools and programmes and which will more and more accurately allow the verification of key areas of the university, e.g. the science area - evaluation of the scientific achievements of the entity. Strategies will include scientific, educational, implementation as well as organisational, market and financial activities. The management information systems at universities are already developing at the moment, enabling quick market and strategic analyses. The management and administration of higher education institutions increasingly use new tools of controlling, process and project management that serve the decision-making process (Hladchenko, 2015).

Strategic management plays a key role in consolidation processes (Pinheiro \& Stensaker, 2014). First of all, the decision about consolidation itself should be preceded by a strategic analysis of the organisation and the environment, which is the premise for making the decision on the merger (Andriuskevicius \& Ciegis, 2017). There should be consultations with various stakeholder and due diligence groups. In the case of a non-public university, making merger decisions is usually faster and simpler. In public universities the decision-making process is usually complex and requires the participation of various stakeholder groups. The strategic objectives of the merger should be set, which will be the basis for the preparation of the strategic plan (planning stage). The adoption of the strategic merger plan is related to the transition to the process of strategic coordination of the merger (implementation stage). Strategic management at this stage consists in drawing conclusions from due diligence and participating in negotiations and concluding contracts (Sulkowski, 2016). Institutionalisation of the merger - in the form of signing agreements and validating the decisions on the consolidation of entities - closes the implementation stage and constitutes the transition to the integration stage (Sarkar \& Perenyi, 2017).

Strategic management consists in planning and implementing decisions regarding the allocation of the entity's resources, aimed at: (1) implementing the strategic goals of the entity, (2) implementing the strategic plan, and (3) increasing the adaptation degree of the entity's activities to the environment. Strategic management of a university, a public one in particular, will serve to achieve goals that are determined by the type of organisation and key stakeholders (Mokhuba \& Govender, 2016). In the case of private entities the founding structure is the decisive body in determining the strategic objectives, while in the case of public universities - university managers, representatives of the staff and students along with political decision-makers (Vilys, Jakubavičius, \& Žemaitis, 2015).

The level of autonomy in making strategic decisions depends on the type of university, its statute and structure of power. Undoubtedly, decisions about mergers belong 
to the strategic level due to their importance and a long time horizon of implementation. Mergers should not be a strategic goal but only a method of achieving it or, possibly, a tactical goal. Strategic goals are the achievements of key importance for the organisation in the long term. The mission of an organisation should reflect the sense of its existence. It is intended to justify the role of the entity both from the point of view of its founders, as well as society, employees and other key stakeholders. The strategic goals and the mission of the university are determined to a large extent by the type of organisation that usually performs a scientific and educational mission and cooperates with the environment (the so-called 'third mission'). The mission and strategic goals of a public university include the implementation of mainly non-commercial aspects of its activity, while non-public, and in particular private, profit-making universities pursue commercial goals (Van der Wende, 2014). According to the assumptions of the planning school, the strategy should be reflected in the strategic plan. The strategic plan includes: (1) strategic objectives, (2) time perspective of the implementation of activities, (3) a sequence of steps (stages) leading to the achievement of the objectives, (4) defining the resources necessary to achieve the objectives and the way they will be used.

\section{MATERIAL AND METHODS}

The research methodology used is of a qualitative nature and is based on a comparative analysis of merger studies between universities. A comparative analysis of university merger cases was conducted on the basis of a set of research indicators developed in the study. In the encoded material from in-depth interviews, statements were sought reflecting the diverse opinions of respondents in relation to research indicators. 13 areas and 31 research indicators were proposed. Then an attempt was made to synthetically compare the cases using all available data obtained with the following techniques: in-depth interviews, documentation analysis, participant observation, auto-ethnography and duo-ethnography. Data obtained from in-depth interviews, the comparison of which made it possible to draw conclusions, turned out to be of key importance. The research presented in the article is of a pilot nature and serves as a preliminary answer to the key questions for the value of the article and effective ways of implementing the consolidation of the university. The attempt of two cases of consolidation of the university was selected on purpose, the choice was based on the criteria of: data availability, literature on the subject and the experience of its authors. The sample is heterogeneous, as it describes university mergers: carried out at different times, between different types of universities, in two countries.

\section{RESULTS AND DESCUSSION}

\section{Case Study 1: Strategic consolidation and the establishment of Université Grenoble Alpes (UGA)}

\section{Characteristics of the Universities}

\section{Université Joseph Fourier}

UJF, also known as Université Grenoble I, was established in 1971 from the transformation of the faculty of science founded in Grenoble by Joseph Fourier in 1811 . The name of Joseph Fourier was born by the university since 1987. This oldest university in 
Grenoble existed until the end of 2015, until it merged with two other universities forming UGA. The University educated 15 000-18 000 students, mainly in the natural, technical and medical sciences, such as: chemistry, biology, geography, physics, computer science, mathematics, medicine and pharmacy.

UJF occupied fairly high positions among French universities in international rankings. In THE ranking in 2012, it ranked 180th and 155th in 2013. It was also in the group of the first 150 world universities and the first ten French universities. Under the decree on the merger of three Universities of Grenoble, which entered into force on January 1, 2016, it became part of the Université Grenoble Alpes.

\section{Université Pierre Mendès France}

Université Pierre Mendès France - Grenoble, operated also under the name Grenoble II and the abbreviation UPMF in 1970-2015. Grenoble II was established in 1970 by the law on higher education from 1968. One of the tendencies that resulted from this regulation was the appearance in France of more specialised research institutes and, at the same time, universities. Grenoble II arose from the separation of a part of the department of humanities and social sciences, including: psychology, sociology and history.

The amendment to the act regulating the functioning of the university in 1984 caused the change of the university statute in the next year. The name 'Pierre Mendès France' (UPMF) was in force since 1991, when the first contract was signed with the Ministry of Higher Education. In 2009, by the agreement in the consortium of PRES Université de Grenoble, UPMF became a member of the Université Grenoble Alpes university group. According to the decree of 2015, the university ceased to exist on January 1, 2016, forming part of a consolidated university under the name Université Grenoble Alpes (UGA).

\section{Université Stendhal}

Université Stendhal (Grenoble III) existed in the years 1970-2015. It was created in 1970 and from the beginning it was named after the famous French writer Stendhal. The university originated from the division of a large department of humanities and social sciences at the University of Grenoble. Grenoble III specialised in research and higher education in the fields of humanities and the fields of art, such as: philology, linguistics, literary studies, cultural studies, social communication, journalism and theatrology. The most important educational programmes were: English philology, French and other philologies, linguistics and other humanities. The university was also traditionally involved in the education of secondary and primary school teachers in the humanities. At the turn of the 20th and 21st centuries, Grenoble III educated about 4000 to 5000 students and about 3000 more in its branches.

\section{The Course of the Merger}

The University of Grenoble was founded in the 14th century (1339) and survived, repeatedly transformed, until 1968. The introduction of a reform strengthening the autonomy of research and teaching centres led to the division of the university into four specialised sister colleges according to the department key. The beginning of the 21st century in France brought 'Shanghai shock', which was associated with the poor positions of French universities in arising and gaining importance in international rankings. Positive consolidation experiences in higher education in many countries encouraged the universities of Grenoble to undertake the pioneering task of joining the universities, which began with the 
creation of a strategic alliance. In 2002, a cooperation was established under the name of Grenoble Universités, which covered all four public universities in Grenoble. In the negotiation process, the University of Technology decided not to move towards the consolidation, while the others planned, communicated and effectively implemented the merger. The Grenoble Universités consortium became an umbrella that enabled the development of cooperation as well as consolidation. In 2003, the ministry proposed a programme of cooperation between the university and the environment, including a consolidation concept. In 2004 Minister Jean Marc-Monteil wrote a letter to the university encouraging the creation of local partnerships with universities and promoting integration. Then, improvement programmes were centrally implemented, which also promoted consolidation.

In 2009, as part of the implementation of the ministerial PRES programme (research and higher education centres), the merger of Universities with Grenoble was announced, which was supposed to start from January 1, 2016. A negotiation and integration team was established, in which representatives of all universities, as well as central and local authorities and external stakeholders participated. Consolidation received strong financial and substantive support from the French Ministry of Higher Education. As a result of strategic analyses, research and negotiations, the following were agreed: the strategy and stages of the merger, the structure of the consolidated university, the new name and the authorities of the consolidated university.

On September 11, 2015 a decree on the merger of three universities in Grenoble was signed, which entered into force on January 1, 2016. By virtue of the decree, the Université Grenoble Alpes was created, which merged three Grenoble universities into one. The university's rector was Lise Dumasy, the rector of Université Stendhal for three tenures. Vicerectors were the managers representing the merging universities. In the restructuring process, a new strategy and organisational structure was created. The new strategy is focused on cooperation with the environment, innovation and implementation, as well as internationalisation and development of high quality research and didactics within a comprehensive university. The mission underlines the growing role of international interdependence, innovation, interdisciplinary research and implementation. It also confirms that the heart of the university's activity is the combination of education and research.

In the consolidation process, a new information system was also implemented, covering the university management, but also the entire scientific output of employees and units, international relations and education quality management. New websites for the university and all units were also created, which was coupled with marketing activities, oriented towards the Internet and social networking sites in particular.

During the consolidation, changes were also made in the area of HR management. A deepened specialisation between research and teaching staff was introduced. Also, evaluation, remuneration and development systems rewarding higher productivity (performance based systems) were introduced. The positions, salaries and development opportunities of employees from different disciplines are differentiated. Representatives of exact, natural and technical sciences gained the greatest chances of development, and humanities and social sciences - slightly smaller.

\section{Merger Barriers}

According to information taken from interviews, the most important barriers to mergers included psychological, social, organisational and legal constraints. From the beginning of 
the process of formalised cooperation, the concerns of the academic staff and administration that consolidation may worsen working conditions or lead to weakening of influence arose. The way to dispel these fears was communication, consultation and providing employees with working conditions that were at least on the same level as before the merger. The staff participated in the preparation of the merger through systematic meetings in the framework of inter-university integration teams for several years. The involvement of employees in the merger was quite high due to the 'Shanghai shock', the chances of using central programmes and the sense of creating a valuable and to some extent pioneering organisational solution in France. A certain social barrier was the formation of groups disturbed by the merger and the conservative attitude of trade unions. Long negotiations, which allowed for a compromise, were necessary. The Technical University of Grenoble, although initially discussed the merger, retreated in the course, mainly due to social resistance. The polytechnic staff did not know if the merger would bring them sufficient benefits to compensate for the partial loss of independence. The merger planning was carried out carefully, as was due diligence. Among the organisational barriers, the key role was played by attachment to the organisational structures and cultures of the universities. The impact of this obstacle was stopped by limiting the restructuring of scientific and didactic units. Departments, institutes, and even chairs remained largely without major changes. The deep transformation concerned support structures. A favourable factor was the early announcement of the consolidation date (2009). Political barriers were rather absent, both the ministry and local authorities favoured consolidation and actively supported it. Some legal limitation was the need to implement many laws and regulations that required time. Financial barriers practically did not appear, because the consolidation was co-financed under the Ministry's programmes.

\section{Merger Effects}

Université Grenoble Alpes currently educates over 45000 students and employs 5500 employees in over 80 organisational units. The merger brought first results in the form of: intensification of scientific activities, improvement of organisational and managerial efficiency and generation of savings from consolidated processes and structures. Naturally, it is difficult to assess the effects of the merger due to the short time of its implementation, but the mere comparison between international rankings before and after the consolidation provides valuable information.

In eight scientific disciplines, UGA is in the world top 50, and in the next nine in the first hundred. In the Leiden (CWTS) ranking, UGA was classified on the 159th place and on the 7th in France. The position in the field of publications in physics, technical sciences, life sciences, earth sciences, mathematics and computer science is particularly high. In the Times Higher Education (THE) ranking, UGA was ranked 52nd in 2017. The QS World University Rankings ranking places UGA in the group of the best universities in 13 scientific disciplines. UGA also received the IDEX scientific excellence certificate. In the Thomson Reuters classification 'Reuters Top 100: The World's Most Innovative Universities' UGA achieved 93th position in the world and 6th in France and 20th in Europe.

\section{Prospects}

The first, positive effects of the consolidation create the prospects for achieving the strategic goals of consolidation in the coming years. UGA implements mechanisms that dyna- 
mise scientific activity, which has improved its position in national and international rankings in the last two years. Much effort was required from the employees to adapt to the new situation, which means that the results of scientific and didactic activities should improve year by year. The interviews indicate improvement of consolidated university management through: more effective strategic management, real emphasis on international cooperation and cooperation with the environment, effective marketing communication and more advanced financial management and accounting. Employees mention faster and more efficient operation of administrative units compared to the situation before the merger. There is a gradual increase in the number of English-speaking students and programmes, which favours the internationalisation of the university. The UGA didactic offer was expanded, and at the same time unified and modernised.

\section{Case Study 2: The merger 'out of sectoral, stimulated from the top necessity' - the Medical University is being created}

\section{Characteristics of the Universities}

\section{Medical Academy in Łódź}

The Medical Academy in Łódź functioned in the years 1949-2002, at the end of its activities the active departments were: medical (including a nursing unit), dental, public health and pharmaceutical (including a branch of medical analytics).

The establishment of the Academy was made possible by the following legal act: Regulation of the Council of Ministers of October 24, 1949 on the creation of medical academies in Warsaw, Krakow, Poznań, Lublin, Łódź and Wrocław. On its basis, the departments operating at the University of Łódź: pharmaceutical, medicine and dentistry joined into an independent university at the beginning of the 1950s. The university ceased to exist in accordance with the Act of the Sejm of the Republic of Poland dated July 27, 2002 on the establishment of the Medical University in Łódź.

\section{Military Medical Academy}

In 1946, the Military and Medical School of Feldshers was established in Łódź, which took over the function of the Chair of Military Medicine, operating in the years 1944-1946 at the Maria Curie-Skłodowska University in Lublin. In 1950, the Military-Medical Faculty for military doctors was established in the structures of the Medical Academy in Łódź, as the foundation for the future Military Academy.

From July 1958, the Military Medical Academy (WAM) existed on the basis of Resolution No. 477/57 of the Council of Ministers of the Polish People's Republic of November 7, 1957 until 2003. It was attended by soldiers - military medical officers (doctors, pharmacists, dentists and psychologists), not only for the needs of the Polish armed forces, but also for forces belonging to other states. The base was the Central Clinical Hospital of the Ministry of National Defence in Łódź. The Academy used the resources of the Medical Academy in Łódź, numerous clinics and chairs were established on the basis of the Academy's civil structure units. Twenty-three independent academics from the Medical Academy were employed at WAM, which also received auxiliary scientific workers, lab technicians and a technical employee. In 1958, the 'Principles of cooperation between the Medical Academy and the Military Medical Academy' were implemented. They regulated the teaching of WAM students 
in medicine and in the field of pharmaceutical studies, employing Medical Academy employees in the Military Medical Academy, sharing facilities needed for conducting classes and research, providing medical equipment, participating in exams and student recruitment. The order of the Ministry of National Defence from May 19, 1958, according to which from the beginning of July the Military Medical Academy, based on the Military Medical Training Centre, was to be created, was also of great importance.

The Academy changed under the influence of the restructuring of the Polish Armed Forces that was taking place since the 1990s. The number of employees, units and students decreased, and there were significant budget restrictions. Under the influence of these changes, WAM became a military-civil university, in 1998-1999 civilians were offered two fields of study: public health and physiotherapy in part-time mode. In view of the reform of the higher military education introduced by the Ministry of National Defence, the Academy actually had to cease to exist, because there was no longer a ministerial training system for military doctors. The Academy authorities began to strive to connect with the Medical University in Łódź to save the status of the university and years of academic work and research.

\section{The Course of the Merger}

Preparations for the merger of universities lasted from 2000. In December that year, the Inter-University Team for Integration was set up, in which the authorities of the University of Łódź participated together with the representatives of the Medical Academy and the Military Medical Academy. Originally, it was planned to combine these three universities in the structures of the Department of Health Sciences of the University of Łódź. This project, however, was not implemented, mainly due to resistance from the medical community and the lack of a solution to the difficult financial situation of many clinical hospitals in Łódź. On the side of the Medical Academy in Łódź, there were concerns that competition in the form of medical departments at the University of Łódź may arise, hence the MA authorities adopted a much more open attitude towards the merger. At the same time, WAM lost its funding base due to a departure from medical military education. This created a compulsory situation in WAM, when the top-down financial pressure forced the university to connect with the other one. The advantage of the merger for both universities was the possibility of prestigious and scientific promotion to the level of the Medical University. On April 8, 2002, a letter of intent was signed regarding the merger of the Medical Academy and the Military Medical Academy and the establishment of the Medical University of Łódź.

\section{Merger Barriers}

The factor conducive to the merger was raising the rank of the consolidated university. Thanks to the merger two academies have become a university. However, despite the prestige promotion, the merger was accompanied by many tensions that had financial, organisational, cultural, social and even personal sources.

Conducted interviews indicate four most important sources of consolidation barriers that occurred during the merger of MA with WAM.

1. Forced and top-down nature of the merger.

2. Problematic situation of a deficit in the activity of many clinical hospitals.

3. Poor preparation for the consolidation process.

4. A sense of threat among scientific, didactic and administrative employees. 
5. Organisational, cultural and personal tensions between universities.

6. Poor financing of the merger and lack of central support in the integration process.

Most of the respondents from the former WAM emphasize that the merger was practically forced, although of course it required the consent of the senates of both universities. WAM could not remain an autonomous university because it did not have adequate sources of central financing. On the other hand, the respondents from former MA emphasize the compulsion of their own situation, because the prospect of establishing medical departments at the University of Łódź was a great source of danger. The merger was topdown, it took place with considerable participation of the central government, because the decisions were taken by the ministers of health and national defence, of course with the approval of both universities. The situation of 'forced consolidation', which resulted from changes in the methods of financing military medical education, created pressure on WAM, which had to make a decision about entering the MA structure. The consequence of this was the negotiation process that led to the creation of the Military and Medical Department. This created the situation of an apparent unification merger. The Medical University was supposed to have a unified, not federal structure, but internal tensions led to the creation of the aforementioned department. The department along with the WAM hospital are the main units employing the staff from the former WAM.

Deficit clinical hospitals strengthened the problem of the merger and practically prevented a wider regional merger between regional universities with the participation of the University of Łódź.

Poor preparation for the consolidation was associated with the lack of analytical and preparatory processes. Before the merger, no strategic analyses had been carried out, and due diligence was lacking. The employees were informed about the merger, but it was not a consultation process. Strategic integration planning was also lacking. The consolidation took place through a one-time parliamentary law and hurried out organisational transformations, which resulted in a smouldering conflict between the group holding power in the former Medical Academy and a group of influence from the Military Medical Academy.

The sense of threat among the scientific-didactic and administrative staff was born out of uncertainty and organisational activities accompanying the merger. The consolidation did not improve the financial position of the consolidated university, which for many years after the merger experienced financial problems related to the construction costs of the Clinic and Didactic Centre (CKD) started in mid-1970s, as well as the deficit related to the operation of clinical hospitals. The consequence were low wages at the Medical University and cost cutting processes that included various groups of employees, including administration and senior lecturers. These were restructurings forced by the financial situation, which increased efficiency, but reinforced the sense of threat for some employees. Low wages meant that the vast majority of teaching staff also worked in other places outside the university.

Organisational, cultural and personal tensions between the employees of the former academies have been going on till this day. Despite 15 years after the merger, interviews with university staff reveal a tension manifested in the antagonism: us and them. It is visible in situations where the most important decisions are taken, for example about choosing the rector. It also involves seeking by the group of influential WAM professors the possibility of making the military-medical structure independent from the Medical University. 
One of the sources of the antagonism is also the great solidarity of the milieu of military doctors, which was strengthened by the 'forced' solution of merger processes.

The consolidation was not accompanied by significant central support. On the contrary, in the following years, the financial pressure on the Medical University increased, related to the costs of completion of the CKD construction and the deficit related to the operation of clinical hospitals. The implemented restructuring was of the cost cutting character, but it did not involve the creation of efficient controlling.

\section{Merger Effects}

Thanks to the merger, the Medical Academy in Łódź became the Medical University, which was a prestigious promotion, resulting from an increase in the scientific and didactic potential. The direct effect was also the broadening of the clinical and didactic base. The merger contributed to improving the rankings, both domestic and international ones. On the other hand, the effect of the merger is the strategic, structural and cultural tension, as well as lasting personal tensions. According to the worldwide ranking of universities, Webometrics Ranking of World Universities in 2013, developed by the Spanish institute Consejo Superior de Investigaciones Científicas, the university took the 7th place in Poland among medical universities, and 2707 in the world from all types of universities.

\section{Prospects}

The integration of both universities is relatively slow and there is a clear distinction between them. The 'military' personnel form their own Military and Medical Department. Ideas are also sought for the possibility of rebuilding and re-separation of military medical education. Quite clear, though remaining within the Medical University, are also tensions between these two groups of influence. The merger did not lead to full integration. The University representatives emphasize that the Military-Medical Department has poor results in the Medical Final Examination, while the graduates of the Department of Medicine of the Medical University have good results.

Mergers between universities, just like in business, do not easily succumb to managerial control and project management, which would enable full implementation of the objectives. Table 1 presents factors determining mergers in higher education.

\section{CONCLUSIONS}

The consolidation of universities is a major theoretical and practical challenge. There is a very large number of practical examples of university mergers in the world, but at the same time a shortage of theory that would help manage consolidations. One of the promising concepts is the social identity approach, other concepts are: M\&A strategic and process theories (Gleibs, Tauber, Viki, \& Giessner, 2013; Cai, 2006). In the public sector, the basis for analysing the concept of consolidation are the theories of new public management (NPM) and public value management (PVM). Nowadays, in the process of university merger research, we are at the induction stage, where hundreds of case studies and few comparative studies have been gathered that draw a complex picture of mergers and can serve as a source of practical guidance. In an attempt to take advantage of these experiences, ten principles of effective management of university mergers that cover the entire process, from planning, through implementation to integration, can be proposed (Figure 1). 
Table 1. Factors Determining Mergers in Higher Education

\begin{tabular}{|c|c|c|}
\hline Factors & Public universities & Private universities \\
\hline \multirow{3}{*}{$\begin{array}{l}\text { Limitations of } \\
\text { the imple- } \\
\text { mentation of } \\
\text { university } \\
\text { mergers }\end{array}$} & conservatism of traditional academic cultures & $\begin{array}{l}\text { organisational culture } \\
\text { adapted to the needs and } \\
\text { strategy of the organisation }\end{array}$ \\
\hline & $\begin{array}{l}\text { strong ethos of academic professions often ori- } \\
\text { ented towards maintaining the status quo }\end{array}$ & \multirow{2}{*}{$\begin{array}{l}\text { moderate ethos, fairly strong } \\
\text { adjustment of the academic } \\
\text { staff to the current require- } \\
\text { ments of the organisation }\end{array}$} \\
\hline & $\begin{array}{l}\text { dominant stakeholder model that fosters a com- } \\
\text { promise between impact groups }\end{array}$ & \\
\hline \multirow{3}{*}{$\begin{array}{l}\text { Factors that } \\
\text { increase the } \\
\text { chance of suc- } \\
\text { cessful mer- } \\
\text { gers }\end{array}$} & $\begin{array}{c}\text { relative homogeneity of merging organisations } \\
\text { (very similar type of activity, similar founding or } \\
\text { ownership structure) }\end{array}$ & $\begin{array}{l}\text { quite limited number of deci- } \\
\text { sion-making stakeholders in- } \\
\text { volved in the merger process }\end{array}$ \\
\hline & $\begin{array}{c}\text { merging, in most cases, universities coming from } \\
\text { one country (lack of far-reaching cultural and legal } \\
\text { differences) }\end{array}$ & $\begin{array}{l}\text { merging universities with the } \\
\text { same educational profile }\end{array}$ \\
\hline & $\begin{array}{l}\text { benefits of the merger that may exist, in many } \\
\text { cases, for all merging universities }\end{array}$ & $\begin{array}{l}\text { benefits of the merger that } \\
\text { may exist, in many cases, for } \\
\text { all merging universities }\end{array}$ \\
\hline \multirow{5}{*}{$\begin{array}{l}\text { Impact on the } \\
\text { dynamics of } \\
\text { the merger } \\
\text { process }\end{array}$} & $\begin{array}{l}\text { competitors in Poland and around the world, po- } \\
\text { tential new competitors and substitutes (other } \\
\text { forms of education, industrial science etc.); }\end{array}$ & \multirow{5}{*}{$\begin{array}{l}\text { the dynamics of the merger } \\
\text { process depends to a large ex- } \\
\text { tent on the factors determin- } \\
\text { ing decision making by deci- } \\
\text { sion-makers participating in } \\
\text { the merger process }\end{array}$} \\
\hline & $\begin{array}{l}\text { cooperation network, consisting of national and in- } \\
\text { ternational entities cooperating with universities }\end{array}$ & \\
\hline & $\begin{array}{l}\text { internal stakeholders, i.e. staff, students and uni- } \\
\text { versity administration; }\end{array}$ & \\
\hline & $\begin{array}{l}\text { external stakeholders, i.e. ministries, central and } \\
\text { local government, employers }\end{array}$ & \\
\hline & $\begin{array}{l}\text { public policy, reflected in the law, university fund- } \\
\text { ing and central and local programmes }\end{array}$ & \\
\hline
\end{tabular}

Source: own study based on the research results.

Mergers and acquisitions belong to complex organisational processes. First of all, because they constitute a radical change which the entire organisation is subjected to in a relatively short time. Despite the rich literature of the subject, many studies and vast practical experience, consolidation processes, in most cases, do not fully achieve the goals or fail. Probably the processes of mergers and acquisitions are too complex, multidimensional and entangled in cultural and social factors to be fully controlled. Running merger processes are very often spontaneous, and the trajectory of revolutionary cultural change becomes partly indeterministic.

In the further environment there are variables that influence the course of the session and the functioning of the universities. Economic factors, such as: living standards, boom, unemployment, have a significant impact on the motivation to start a merger. One can risk a thesis that the deterioration of the country's economic situation should become a catalyst for a wave of mergers, especially in dispersed higher education systems. Demographic variables, related to fertility and the flow of human capital, form the basis for assessing the demand for higher education at the national level. Lower demand for studies is one of 


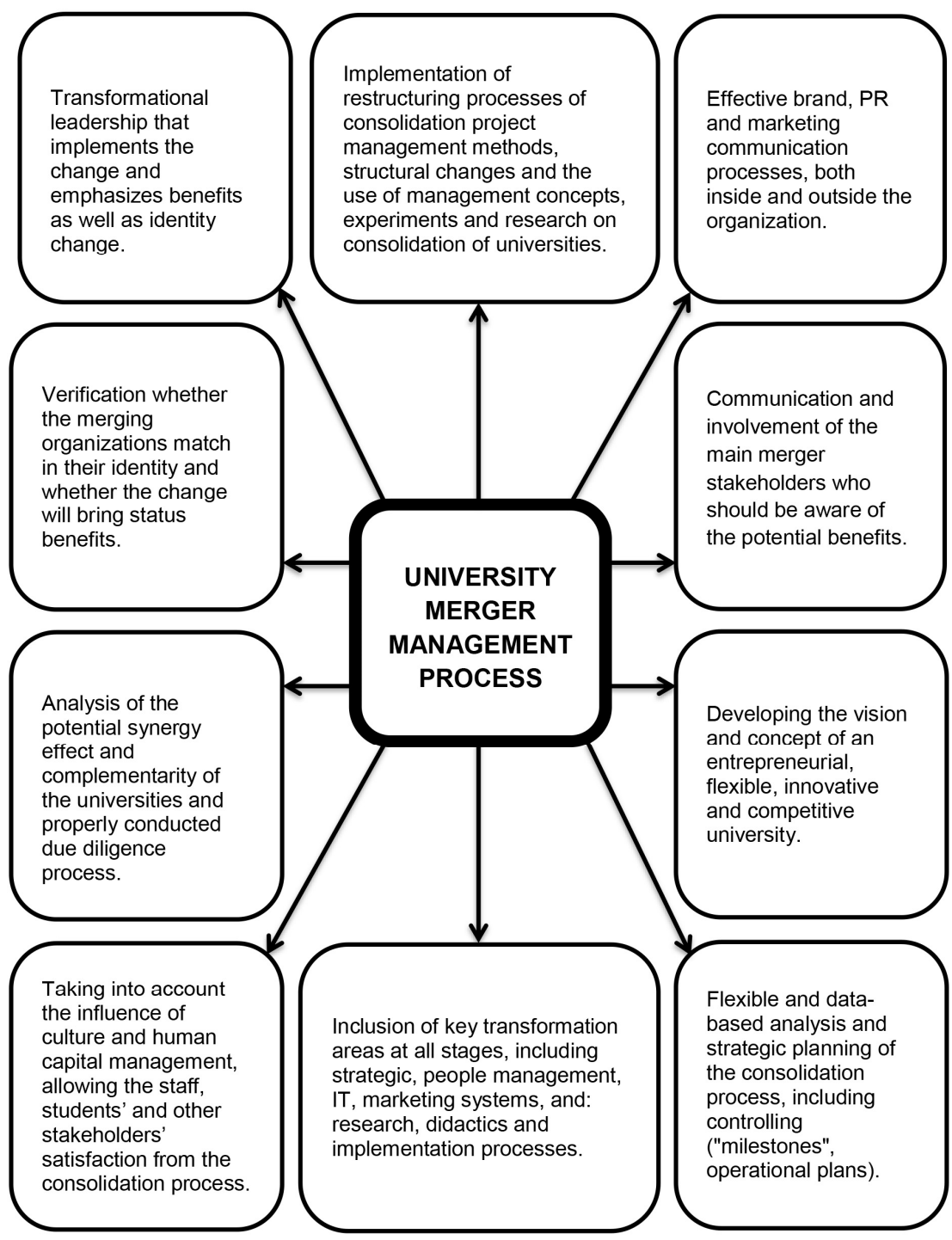

Figure 1. The process of university management process

Source: own study based on the research results.

the reasons for consolidation of universities, which can be observed, for example, in Poland, Romania and the Baltic States (Rădulescu, Rădulescu, Ovidiu, Rădulescu, Rădulescu, \& Naş, 2016). Social factors relate to the level and structure of scholarisation in a given country. Social patterns have a significant impact on decisions to study and choose a programme, with the transformation from an elite to an egalitarian higher education system into a global megatrend. The waves of systemic mergers, carried out, among others, in China, EU countries and the USA in the 1990s, were designed to better adapt to the mass and even universal model of education (Mao, Du, \& Liu, 2009). The cultural context also 
has a significant impact on consolidation processes, although the assessment of its impact is very difficult. Culture not only shapes the organisations themselves and the behaviour of people in organisations, but also affects the functioning of the entire education system, and even the dynamics of the consolidation process. In countries with high levels of social capital, with developed civic culture, university mergers are more likely to be successful. However, there are positive and negative examples that contradict this thesis. Successful centralist mergers in China, on the one hand, prove that even in a society with a relatively low civic culture, it is possible to effectively implement the consolidation of universities (Cai \& Yang, 2016). On the other hand, some failed mergers in the UK and Australia prove that culture is only one of the variables in the complex mosaic of impact factors (Martin, 1996). An important role in the processes of university consolidation is also played by the scientific and technological environment. It is connected with the progress of science requiring the reorganisation of research units, which takes place through internal restructuring, the creation of cooperation networks and mergers. The general tendency is the concentration of scientific units, which leads to the creation of a 'critical mass' that allows the implementation of ambitious research projects and the development of renowned scientific schools. New technologies emerge in the cooperation of universities with the industry and through the creation of spin-offs. One of the consolidation motivations in France was to build strong links between universities and enterprises, which is supposed to fuel economic, scientific and technological development. New communication and network technologies also have direct impact on conducting research (e.g. methods, laboratories) and education (e.g. on-line education). Distance education opportunities were one of the motives for combining even distant campuses and colleges. Global variables are related to the internationalisation of science and higher education and the development of global competition. One of the key mechanisms to drive a wave of strategic mergers in the public university sector that is sweeping through the world are global rankings, such as: Academic Ranking of World Universities - Shanghai Ranking Consultancy, World's Best Universities Ranking - US News \& World, THE World University Ranking - Times Higher Education, U-Multirank. In globalisation, English-speaking countries (USA, United Kingdom, Australia) have a competitive advantage due to the international role of English and the academic and educational position of their universities. In many countries, mergers are carried out to internationalise the university by: opening joint programmes (joint, dual and double degrees) and English-language programmes, attracting foreign students, strengthening academic and didactic exchange. Knowledge capital means the development of competences regarding the consolidation of universities based on research projects taken not only from the education sector, but also from business, as well as from experience and studies of merger cases. The growing number of publications, research and cooperation projects convinces that consolidations may lead to the implementation of many strategic goals and may affect both private and public universities. Knowledge about potential risks and threats of consolidation processes is also better, which allows to plan future mergers more effectively.

The example of consolidation - Grenoble - indicates that the return to the identity and heritage of the University of Grenoble from over 40 years was a strong integrator. The opposite situation occurred in the case of the second described study - AM with WAM. In this case, the merger did not lead to full integration. In the case of UGA mergers, all support 
structures have been designed and implemented as university-wide and integrated units. There was also a high degree of interaction and cooperation within the inter-faculty matrix structures. Consolidations should also develop effective human capital management. An example is the diversification of career paths, which occurred, for example, in UGA during consolidation. In the case of the merger of AM with WAM there were many barriers affecting the merger. Some of them concerned the area of human resources (organisational, cultural and personnel tensions between universities) and the finances of entities.

\section{REFERENCES}

Andriuskevicius, K., \& Ciegis, R. (2017). Developments and challenges of measuring M\&A performance on a corporate and macroeconomic levels. Oeconomia Copernicana, 8(2), 199-220. https://doi.org/10.24136/oc.v8i2.13

Benington, J., \& Sørensen, E. (2017). Towards a multi-actor theory of public value co-creation. Public Management Review, 19(5). https://doi.org/10.1080/14719037.2016.1192164

Cai, Y. (2006). A case study of academic staff integration in a post-merger Chinese university. Tertiary Education and Management, 12(3). https://doi.org/10.1007/s11233-006-9002-7

Cai, Y. (2016). Towards a novel conceptual framework for understanding mergers in higher education. European Journal of Higher Education, 6(1), 7-24. https://doi.org/10.1080/21568235.2015.1099457

Cai, Y., \& Yang, X. (2016). Mergers in Chinese higher education: lessons for studies in a global context. European Journal of Higher Education, 6(1), 71-85. https://doi.org/10.1080/21568235.2015.1099458

Gleibs, I.H., Tauber, S., Viki, G.T., \& Giessner, S.R. (2013). When What We Get Is Not What We Want The Role of Implemented Versus Desired Merger Patterns in Support for Mergers. Social Psychology, 44(3), 215-226. https://doi.org/10.1027/1864-9335/a000102

Hartleyi, J. (2017). Towards an empirical research agenda for public value theory. Public Management Review, 19(5), 670-685. https://doi.org/10.1080/14719037.2016.1192166

Hladchenko, M. (2015). Balanced Scorecard - a strategic management system of the higher education institution. International Journal of Educational Management, 29(2), 167-176. https://doi.org/10.1108/IJEM-11-2013-0164

Karodia, A.M., Shaikh, A., \& Soni, D. (2015). The South African universities post-merger mess: Problems and challenges of transformation. Mediterranean Journal of Social Sciences, 6(3), S1. https://doi.org/10.5901/mjss.2015.v6n3s1p326

Mačerinskienè, I., \& Aleknavičiūtè, R. (2017). National intellectual capital influence on economic growth in the European Union countries. Equilibrium. Quarterly Journal of Economics and Economic Policy, 12(4), 573-592. https://doi.org/10.24136/eq.v12i4.30

Mao, Y., Du Y., \& Liu J. (2009). The effects of university mergers in China since 1990s: From the perspective of knowledge production. International Journal of Educational Management, 23(1). https://doi.org/10.1108/09513540910926402

Martin, C.D. (1996). The involuntary push: University mergers and their effect on post-graduate management education in South Australia. Journal of Educational Administration, 34(3), 83-91.

Mihi-Ramírez, A. (2016). Trends in the International Academic Migration: A Case of Spain. Entrepreneurial Business and Economics Review, 4(1), 113-128. https://doi.org/10.15678/EBER.2016.040108

Mokhuba, D.K., \& Govender K. (2016). The merger of historically disadvantaged tertiary institutions in South Africa: A case study of the University of Limpopo. Cogent Business \& Management, 3(1), 125-133. 
Pinheiro, R., \& Stensaker, B. (2014). Strategic Actor-Hood and Internal Transformation. In B. Jelena, M. Klemenčić, P. Lažetić, \& P. Zgaga (Eds.), Global Challenges, Local Responses in Higher Education (pp. 171-189), Sense Publishers. https://doi.org/10.1007/978-94-6209-581-6

Pinheiro, R., Geschwind, L., \& Aarrevaara, T. (2016). Mergers in Higher Education. European Journal of Higher Education, 6(1), 2-6. https://doi.org/10.1007/978-3-319-21918-9

Rădulescu, C., Rădulescu, G.M.T., Ovidiu, S., Rădulescu, A.T.G.M., Rădulescu, V.M.G.M., \& Naş, S. (2016). The Access to Performance in Romanian Academic System Possibilities for iliescu the Competitiveness of Universities in Romania. DEStech Transactions on Social Science, Education and Human Science.

Sarkar, Á., \& Perényi, A. (2017). Education Agents as Competitiveness Enhancers of Australian Universities by Internationalisation Facilitation. Entrepreneurial Business and Economics Review, 5(4), 61-89. https://doi.org/10.15678/EBER.2017.050403

Seliga, R., Sulkowski, L., \& Wozniak, A. (2019). Barriers to University Mergers - Comparative analysis of Universities in Europe. Advances in Intelligent Systems and Computing, vol. 783, AHFE. 558567. https://doi.org/10.1007/978-3-319-94709-9_55

Soni, S., \& Govender, K. (2018). The Relationship between Service Quality Dimensions and Brand Equity: Higher Education Students' Perceptions. Journal of Management and Business Administration. Central Europe, 26(3), 71-87.

Sułkowski, Ł. (2016). Accountability of University: Transition of Public Higher Education. Entrepreneurial Business and Economics Review, 4(1), 9-21. https://doi.org/10.15678/EBER.2016.040102

Tourish, D., Craig, R., \& Amernic, J. (2017). A mania for assessment. The Corporatization of the Business School: Minerva Meets the Market, 34.

Van der Wende, M.C. (2014). On mergers and missions: Implications for institutional governance and government steering. In Q. Wang, Y. Cheng, \& N. Cai Liu (Eds.), Global Outreach of WorldClass Universities: How It is Affecting Higher Education Systems (pp. 137-153). Centre for WorldClass Universities, Jiao Tong University, Shanghai, Sense Publishers.

Vilys, M., Jakubavičius, A., \& Žemaitis, E. (2015). Public Innovation Support Index for Impact Assessment in the European Economic Area. Entrepreneurial Business and Economics Review, 3(4), 123-138. https://doi.org/10.15678/EBER.2015.030408 


\section{Authors}

The contribution share of authors is equal and amounted to $33,3 \%$ each of them.

\section{Łukasz Sułkowski}

Professor of economics and humanities. Chair of HEI Management Department at Jagiellonian University in Cracow, at Clark University (USA) and at the University of Social Sciences. He was the main investigator of 11 research grants (including grants from the State Committee for Scientific Research, the National Science Centre and European Union). Holds numerous awards from the Rector of the Jagiellonian University, Clark University and University of Social Sciences. Łukasz Sułkowski specialises in management sciences.

Correspondence to: Prof. Łukasz Sułkowski, Jagiellonian University, Institute of Public Affairs, ul. prof. St. Łojasiewicza 4, 30-348 Kraków, Poland, e-mail: lukasz.sulkowski@uj.edu.pl ORCID 가 http://orcid.org/0000-0002-1248-2743

\section{Robert Seliga}

Assistant Professor, He obtained his master's degree in management and marketing from the University of Social Sciences in Lodz. In 2009 he obtained his PhD in economic sciences. Robert Seliga specialises in management sciences.

Correspondence to: Dr Robert Seliga, University of Social Sciences in Lodz, ul. Sienkiewicza 9, 90-113 Łódź, Poland, e-mail: rseliga@san.edu.pl

ORCID ㄴ http://orcid.org/0000-0003-3306-904X

\section{Andrzej Wozniak}

Assistant Professor, He obtained his master's degree in management and marketing from the University of Social Sciences in Lodz. In 2013 he obtained his PhD in economic sciences. Andrzej Wozniak specialises in management sciences.

Correspondence to: Dr Andrzej Wozniak, University of Social Sciences in Lodz, ul. Sienkiewicza 9, 90-113 Łódź, Poland, e-mail: awoznak@san.edu.pl

ORCID i http://orcid.org/0000-0002-9816-047X

\section{Acknowledgements and Financial Disclosure}

The article is financed from the project DIALOG no. 0146/2017 entitled „Doskonalenie organizacyjne uczelni przyszłości (UNIFUT.PL)" (University of the Future).

\section{Copyright and License}

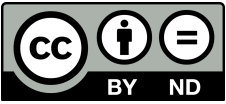

This article is published under the terms of the Creative Commons

Attribution - NoDerivs (CC BY-ND 4.0) License http://creativecommons.org/licenses/by-nd/4.0/

Published by the Centre for Strategic and International Entrepreneurship - Krakow, Poland 
